\title{
ESPAÇOS NÃO-FORMAIS, ESTUDO DO LUGAR E EDUCAÇÃO EMANCIPATÓRIA: (RE)SIGNIFICANDO SENTIMENTOS E VALORES SOBRE FEIRA DE SANTANA
}

\author{
Daiane Correia de Vasconcelos ${ }^{1}$; Cléa Cardoso da Rocha ${ }^{2}$ \\ 1. Bolsista PROBIC/UEFS, Graduando em Licenciatura em Geografia, Universidade Estadual de Feira de \\ Santana, e-mail: daianevasconcelos@yahoo.com.br \\ 2. Orientadora, Departamento de Educação, Universidade Estadual de Feira de Santana, e-mail: \\ cleabase@yahoo.com.br
}

PALAVRAS-CHAVE: educação geográfica; espaços educativos não-formais; lugar.

\section{INTRODUÇÃO}

A educação deve estar voltada para a vida, servindo à libertação humana, fundada na criatividade e estimulando a reflexão e a ação verdadeiras dos homens sobre a realidade (FREIRE, 1987; 1997), para que possa interferir conscientemente sobre sua realidade sócio-espacial, em constante transformação e, com isso, “[...] permitir ao homem chegar a ser sujeito, construir-se como pessoa, transformar o mundo, estabelecer com os outros homens relações de reciprocidade, fazer a cultura e a história" (FREIRE, 1980, p. 39). Nesse contexto, faz-se necessário que a educação ocorra para além dos muros da escola, apropriando-se também de espaços não-formais, que, segundo Gohn (1999; 2014) tem como um dos pressupostos básicos que a aprendizagem ocorra através da prática social e, consequentemente, do intercâmbio social, na perspectiva de trazer a realidade do educando para o processo educativo, já que se constitui como um ponto de partida para o desenvolvimento de competências e habilidades da educação formal.

No contexto educacional atual, faz-se necessário discutir o papel da escola e repensar as possibilidades educativas que possam contribuir na preparação do educando para a vida, de modo que contribua para a (re)valorização da geografia a partir do estudo do lugar de vivência dos educandos. É preciso ensinar o educando a pensar, tendo em vista a realidade social, cultural e política do contexto que este se encontra inserido, e provocar a curiosidade e interação com os objetos de estudo. Acredita-se que uma das possibilidades pedagógicas que pode contribuir para o desenvolvimento de competências e habilidades, de modo que ofereça condições para que o aluno esteja apto para a vida, seja o desenvolvimento de ações educativas em museus por ser um lugar de memórias e valorização de cultura.

Os museus têm como uma das suas funções "[...] situar todo e qualquer homem como agente de sua própria história” (BENCHETRIT; BEZERRA; CHAGAS, 2008, p. 7), de modo que favoreça a sua atuação no “[...] desenvolvimento social, possibilitando caminhos que conduzem à reflexão, à produção de conhecimentos e ao desenvolvimento de uma consciência crítica" (op. cit.), como pressupõe uma educação libertadora. Desta forma, este espaço educativo não-formal pode possibilitar ao educando reconhecer-se como sujeito da realidade sócio-espacial constantemente transformada e contribuir para a (re)significação de sentimentos e valores, do sujeito e do seu reconhecimento como parte de um grupo social, o que requer o compartilhamento de memórias.

A partir do exposto pretendeu-se responder através desta pesquisa ainda em andamento, os questionamentos: De que forma o Museu Casa do Sertão pode contribuir 
para o ensino-aprendizagem de geografia? Qual a relação do Museu Casa do Sertão com a construção/fortalecimento de identidades, sentimentos, significados, valores e outras características subjetivas com Feira de Santana, enquanto lugar de vivência? Quais as possibilidades e os desafios do uso do Museu Casa do Sertão enquanto mediador na construção de conhecimentos geográficos?

$\mathrm{Na}$ tentativa de responder aos questionamentos supracitados está sendo desenvolvida uma pesquisa de caráter qualitativo e extensionista, no âmbito do Museu Casa do Sertão, objetivando criar uma tela interativa que simule o espaço do museu, contemplando informações sobre as coleções através do tour virtual. Esta experiência virtual tem a pretensão de reforçar o papel educativo do Museu Casa do Sertão ao possibilitar o aprofundamento dos conhecimentos do visitante com o auxílio da tela interativa, bem como contribuir para sua função social a partir da (re)significação de sentimentos e valores sobre Feira de Santana enquanto lugar.

\section{MATERIAL E MÉTODOS}

Para o desenvolvimento desta pesquisa serão empregados métodos que estão em consonância com o projeto "Lugar: Formação Docente e Elaboração de Material Didático Pedagógico Sobre Feira de Santana/BA", que é uma pesquisa qualitativa de caráter também extensionista. Dessa maneira, com finalidade de atender aos objetivos propostos lançou-se mão de: 1. Levantamento bibliográfico sobre as temáticas abordadas pela pesquisa (educação geográfica, lugar, espaços educativos não-formais, museu, lugares de memória, entre outros) e pela tela interativa (Museu Casa do Sertão, couro, cerâmica, Crispina dos Santos, Lucas da Feira, sertão, entre outros); 2. Discussão teórica com grupo de pesquisa através dos encontros quinzenais no Grupo de Estudos do Projeto Lugar; 3. Elaboração da tela interativa; 4. Sistematização e análise dos dados coletados; 5. Elaboração de relatórios e publicação dos resultados.

\section{RESULTADOS E/OU DISCUSSÃO}

\section{Acompanhamento das visitas no Museu Casa do Sertão}

Para a elaboração da tela interativa fez-se necessário o acompanhamento das visitas no Museu Casa do Sertão para compreender quais grupos frequentam este espaço, quais os interesses e curiosidades ao visitar este espaço e a significância atribuída à este, com vistas a contribuir no planejamento e construção que pudesse atender a todo o público. Durante o acompanhamento das visitas ao Museu Casa do Sertão, observou-se que os questionamentos realizados pelos visitantes em sua maioria se restringem à curiosidades acerca do que é e para que servem os objetos expostos. Quanto mais jovem o público é, mais eles percebem o museu como um espaço de diversão. Os demais públicos interpretam como um espaço cultural e que muitas vezes remetem às suas vivências cotidianas.

Dentre os espaços observou-se a exposição intitulada "A feira de Feira de Santana: transformações e permanências", o que mais despertou a curiosidade dos visitantes para que estes fizessem questionamentos para além de "o que é?" ou "para que serve?" foi a abordagem sobre a feira livre de Feira de Santana, desde os primórdios até os dias atuais. Surgiram muitas inquietações acerca da resistência dos feirantes no momento de mudança de local da feira livre, bem como sobre os demais acontecimentos que ocorriam neste espaço. Para além disso, alguns visitantes questionaram também 
sobre como se efetuava o comércio naquela época em relação aos pagamentos e também a respeito do que era comercializado.

Outro espaço que chamou a atenção dos visitantes foi a ambientação da casa, sobretudo o quarto, que quase todos questionavam como era possível dormir com tão pouco conforto. Outro aspecto interessante do quarto, que foi observado tanto no público de crianças/adolescentes quanto nos adultos, é que assim que eles perceberam os objetos utilizados para alisar ou moldar os cabelos se impressionavam e alguns comentaram sobre os padrões de beleza que já eram impostos há muito tempo atrás.

Notou-se que a depender da faixa etária os questionamentos se diferenciavam quantitativamente e em relação ao tema também, pois as crianças e os adolescentes observados eram mais curiosos e questionadores, no entanto nem todos conseguiam fazer uma relação dos objetos com experiências familiares ou do seu cotidiano. Já os adultos e os idosos são menos questionadores, em contrapartida eles conseguem relacionar com suas experiências vividas e muitos objetos inclusive faz parte do cotidiano deles.

2. Planejamento da tela interativa

As observações das visitas guiadas no Museu Casa do Sertão deram suporte tanto no que se refere ao público que iria fazer uso da tela interativa, quanto quais elementos seriam mais interessantes para serem abordados na tela interativa. Como o público é bastante diversificado, optou-se por uma tela interativa que seja de fácil manuseio, para que todos possam utilizá-la, e que também possa ser atualizada com facilidade. Assim, foi escolhido o DocPro que consiste numa biblioteca inteligente que permite a socialização do acervo, de fácil manuseio e alimentação. No entanto, embora tenham sido feitas várias tentativas de contato não houve uma resposta da equipe fornecedora, visto que isso é necessário pois o software DocReader não é comercializado. Diante desse entrave foi escolhido uma alternativa, o PowerPoint, para a elaboração da versão preliminar da tela interativa. Para além disso, também foram realizadas visitas à biblioteca para leitura de obras do acervo sobre as temáticas selecionadas para a tela interativa.

A versão preliminar da tela interativa foi elaborada seguindo a estrutura: 1) Museu Casa do Sertão: para abordar o que é o museu, quando e com qual finalidade foi fundado; 2) A Casa do Sertão: fala sobre o conceito de sertão na perspectiva geográfica; 3) A ambientação da casa: fala como está organizada a casa e sobre seus elementos; 4) Couro: fala sobre a sua relevância no que se refere à cultura popular feirense e os principais artefatos; 4.1) Vaqueiro: aborda a importância desta profissão para cultura feirense que se faz presente até os dias atuais; 5) Cerâmica: fala sobre a sua relevância no que se refere à cultura popular feirense e os principais artefatos; 5.1) Crispina Santos: fala da importância desta ceramista para a cultura popular feirense e de que forma suas obras refletem elementos identitários de Feira de Santana; 7) Lucas da Feira. 3. Proposta de oficina

Após a elaboração e experienciação da tela interativa, será realizada uma oficina na perspectiva de utilizar a tela como um recurso didático-pedagógico para a construção do conhecimento geográfico. Para isso, será realizada no espaço do Museu Casa do Sertão a exposição intitulada "OLHARES SOBRE A CIDADE DE FEIRA DE SANTANA". Tendo como objetivo: Despertar um olhar criativo sobre o polissêmico conceito de cidade e para o que nossos olhos já estão acostumados, com detalhes da cidade que nos passam despercebidos, para assim conhecer a cidade, entendê-la, discutila, conscientizar-se acerca da cidade e então (re)significar sentimentos e valores sobre Feira de Santana. Esta exposição será desenvolvida tendo como premissa a tríade Cidade-Patrimônio-Museu, na perspectiva de "desnaturalizar os olhares sobre a cidade", 
como sugere Freitas (2014), a partir do entrecruzamento dos conceitos de cidadeartefato $^{1}$, ressonância ${ }^{2}$, materialidade e subjetividade.

\section{CONSIDERAÇÕES FINAIS}

A partir da coleta de dados realizada nesta pesquisa notou-se que embora o museu seja um espaço educativo não-formal, muitos ainda o percebem como um espaço de lazer. Este espaço tem papel fundamental na (re)significação de sentimentos e valores de seus visitantes por Feira de Santana, sobretudo por aqueles que de fato viveram num período em que os artefatos e as histórias apresentadas lá faziam parte do seu cotidiano, a exemplo dos idosos que frequentam o museu. No que se refere às outras faixas etárias, a exposição temporária em virtude os 40 anos de mudança das feiras livres que mais se destaca com esse papel é do que retrata a feira livre de Feira de Santana, devido ao contato enquanto consumidor, ou até mesmo àqueles que vivem do sustento proveniente dessas feiras.

A presente pesquisa consta com atividades em andamento devido às dificuldades encontradas, dentre as quais destacam-se: As paralisações que ocorreram ao longo do último ano que dificultaram o acesso ao campus, necessário para o cumprimento dos objetivos, visto a necessidade do acesso ao museu e a biblioteca para o desenvolvimento da pesquisa; Dificuldade em encontrar um software ou plataforma digital que possibilitasse a socialização da tela interativa com todos e que não necessitasse de internet para o seu uso no âmbito do Museu Casa do Sertão, devido à internet da instituição que não funciona regularmente; Após vários estudos para escolher qual seria o software ideal, encontrou-se o DocPro, que é um software pago, portanto necessitava entrar em contato com os desenvolvedores para a compra (para doá-lo ao museu), e até então não houve retorno, depois de meses de tentativas de contato.

\section{REFERÊNCIAS}

BENCHETRIT, Sarah Fassa; BEZERRA, Rafael Zamorano; CHAGAS, Mario de Souza. A Democratização da Memória: A Função Social dos Museus Ibero-Americanos. Rio de Janeiro: Museu Histórico Nacional, 2008.

FREIRE, Paulo. Conscientização: teoria e prática de libertação: uma introdução ao pensamento de Paulo Freire. 3. ed. São Paulo: Moraes, 1980.

. Pedagogia do oprimido. 17. ed. Paz e Terra:Rio de Janeiro, 1987.

Terra, 1997.

Pedagogia da autonomia: saberes necessários àprática educativa. São Paulo: Paz e

GOHN, Maria da Glória. Educação não-formal e cultura política: impactos sobre o associativismo do terceiro setor. São Paulo: Cortez, 1999.

. Educação não formal, Aprendizagens e Saberes em Processos Participativos.

Investigar em Educação, v. 2, n. 1, p. 35-50, 2014.

\footnotetext{
1 “[...] é a cidade entendida como patrimônio, que não corresponde mais à imagem estática, "pasteurizada", "asséptica" e "chapada" da fotografia postal, ou seja, da imagem produzida para consumo, como cidade que prescinde da experiência." (FREITAS, 2014, p. 4)

2 “[...] corresponde ao fio, quase mágico, que se estabelece e liga o sujeito ao seu patrimônio. [...] Aplicando tal entendimento à temática da cidade, constatamos que é essa força que nos faz ter a certeza de que pertencemos àquela cidade e, ao mesmo tempo, que ela nos pertence.” (FREITAS, 2014, p. 5)
} 